\title{
Inhibition of renin-angiotensin system affects prognosis of advanced pancreatic cancer receiving gemcitabine
}

\author{
Y Nakai', H Isayama*,', H ljichi', T Sasaki', N Sasahira', K Hirano', H Kogure', K Kawakubo', H Yagioka', \\ Y Yashima', S Mizuno', K Yamamoto', T Arizumi', O Togawa', S Matsubara', T Tsujino', K Tateishi', M Tada', \\ M Omata ${ }^{2}$ and K Koike' \\ 'Department of Gastroenterology, Graduate School of Medicine, The University of Tokyo, 7-3-I Hongo Bunkyo-ku, Tokyo I I 3-8655, Japan; ${ }^{2}$ Yamanashi \\ Prefectural Central Hospital Organization, I-I - I Fujimi, Kofu, Yamanashi 400-8506, Japan
}

BACKGROUND: The renin-angiotensin system (RAS) is thought to have a role in carcinogenesis, and RAS inhibition may prevent tumour growth.

METHODS: We retrospectively investigated the impact of angiotensin I-converting enzyme inhibitors (ACEls) and angiotensin II type-I receptor blockers (ARBs) in 155 patients with pancreatic cancer receiving gemcitabine monotherapy. Patients were divided into three groups: the ACEI/ARB group (27 patients receiving an ACEI or ARB for hypertension (HT)), the non-ACEI/ARB with HT group (25 patients receiving antihypertensive drugs other than ACEls or ARBs), and the non-HT group ( 103 patients receiving no antihypertensive drugs).

RESULTS: Patient characteristics were not different, except for age and HT medications. Progression-free survival (PFS) was 8.7 months in the ACEI/ARB group, 4.5 months in the non-ACEI/ARB with HT group, and 3.6 months in the non-HT group. Overall survival (OS) was I5.I months in the ACEI/ARB group, 8.9 months in the non-ACEI/ARB with HT group, and 9.5 months in the non-HT group. The use of ACEls/ ARBs was a significant prognostic factor for both PFS $(P=0.032)$ and $O S(P=0.014)$ in the multivariate analysis.

CONCLUSIONS: The ACEIS/ARBs in combination with gemcitabine might improve clinical outcomes in patients with advanced pancreatic cancer. Prospective trials are needed to test this hypothesis.

British Journal of Cancer (2010) I 03, 1644-1648. doi: I0.1038/sj.bjc.6605955 www.bjcancer.com

Published online 26 October 2010

(C) 2010 Cancer Research UK

Keywords: angiotensin I-converting enzyme inhibitors; angiotensin II type- I receptor blockers; chemotherapy; gemcitabine; pancreatic cancer; renin-angiotensin system

Systemic administration of gemcitabine has been the standard chemotherapy for advanced pancreatic cancer since Burris et al (1997) demonstrated the superiority of gemcitabine over 5-flurouracil. Combination therapies of gemcitabine with other cytotoxic drugs (Berlin et al, 2002; Louvet et al, 2005; Herrmann et al, 2007; Cunningham et al, 2009; Nakai et al, 2009, 2010) have been thoroughly investigated, but only two randomised control trials have shown significant improvements in the survival so far (Reni et al, 2005; Conroy et al, 2010). Many molecular target drugs have been recently investigated in clinical trials (Van Cutsem et al, 2009; Kindler et al, 2010; Philip et al, 2010). Erlotinib in combination with gemcitabine was the only drug that showed prolonged survival in advanced pancreatic cancer (Moore et al, 2007) but the survival benefit was modest, with only a 2-week improvement in survival, and was accompanied by high costs and greater toxicity than gemcitabine alone. Thus, more effective and safe drugs are awaited.

The systemic renin - angiotensin system (RAS) is associated with cardiovascular regulation and angiotensin I-converting enzyme inhibitors (ACEIs) and angiotensin II type-1 receptor blockers (ARBs) are some of the most widely used antihypertensive drugs.

*Correspondence: Dr H Isayama; E-mail: isayama-2im@h.u-tokyo.ac.jp Received I September 2010; revised 17 September 2010; accepted 22 September 2010; published online 26 October 2010
Since Lever et al (1998) reported that the use of ACEI was associated with a decreased incidence of cancer in a large cohort study, the potential role of the local RAS in carcinogenesis has attracted substantial attention. The local RAS reportedly promotes angiogenesis and proliferation via vascular endothelial growth factor (VEGF) expression or epidermal growth factor receptor (EGFR) expression (Ager et al, 2008; Khakoo et al, 2008). Synergistic inhibition of tumour growth in a murine pancreatic cancer has been demonstrated with combined gemcitabine and losartan treatment via VEGF suppression (Noguchi et al, 2009). In addition, the inhibition of RAS is also reported to induce apoptosis in pancreatic cancer cells (Amaya et al, 2004; Gong et al, 2010). Thus, the use of ACEIs or ARBs may inhibit tumour growth in patients with pancreatic cancer. In this study, we retrospectively analysed clinical outcomes in patients with pancreatic cancer receiving gemcitabine monotherapy to clarify the impact of ACEIs and ARBs.

\section{PATIENTS AND METHODS}

\section{Patients}

All patients with locally advanced and metastatic pancreatic cancer who received first-line chemotherapy with gemcitabine monotherapy without previous treatment, including surgical resection 
and radiotherapy at the University of Tokyo Hospital between April 2001 and August 2009 were retrospectively studied. The use of hypertension (HT) medications including ACEIs or ARBs was retrospectively retrieved from the medical records, and patients were divided into three groups: the ACEI/ARB group (patients who received ACEIs or ARBs for $\mathrm{HT}$ ), the non-ACEI/ARB with $\mathrm{HT}$ group (patients who received antihypertensive drugs other than ACEIs or ARBs), and the non-HT group (patients who did not receive antihypertensive drugs). This study was approved by The University of Tokyo Hospital ethics committee.

\section{Treatment and tumour response}

Gemcitabine was administered at a dose of $1000 \mathrm{mg} \mathrm{m}^{-2}$ in a 30 -min intravenous infusion on days 1,8 , and 15 in 4 -week cycles. The relative dose intensity (RDI) for gemcitabine was defined as the ratio of the actual dose intensity to the standard dose intensity. Tumour response was assessed via computed tomography using the Response Evaluation Criteria in Solid Tumours version 1.0 (Therasse et al, 2000). The evaluation was repeated every two courses, or more frequently in patients with clinically suspected progression.

\section{Statistical methods}

Overall survival (OS) and progression-free survival (PFS) were estimated using the Kaplan-Meier method and compared using the log-rank test. The $\chi^{2}$-test or Fisher's exact test was used to compare categorical variables. The independent $t$-test, MannWhitney $U$-test, or Kruskal-Wallis test was used to compare continuous variables as appropriate. All reported $P$-values were the result of two-sided tests, with $P<0.05$ considered statistically significant.

To exclude possible confounding factors, the Cox proportional hazards model was used to estimate hazard ratios of the use of ACEIs/ARBs adjusted for significant prognostic factors. Prognostic factors included age $(<65$ or $\geqslant 65$ years old), gender (male or female), performance status (PS; $0-1$ or $\geqslant 2$ ), distant metastasis (yes or no), pretreatment carbohydrate antigen 19-9 level, and treatment group (the ACEI/ARB group, the non-ACEI/ARB with HT group, or the non-HT group). Prognostic factors with $P<0.05$ in the univariate analysis were included in the multivariate analysis.

\section{RESULTS}

\section{Patients' characteristics}

In total, 155 patients received first-line gemcitabine monotherapy between April 2001 and August 2009 at The University of Tokyo Hospital, with a median follow-up time of 9.5 months. In all, 52 patients received medication for HT (Table 1) and of these, 27 patients took an ACEI $(n=6)$ or ARB $(n=21)$. Other antihypertensive drugs included calcium-channel blockers $(n=22)$ and $\beta$-blockers $(n=3)$. The most commonly administered drug was candesartan $(n=12)$. The doses of ACEIs and ARBs were as follows: enalapril $5 \mathrm{mg}$ in three patients and $2.5 \mathrm{mg}$ in one patient, lisinopril $10 \mathrm{mg}$ in one patient, temocapril $4 \mathrm{mg}$ in one patient, candesartan $4 \mathrm{mg}$ in eight patients and $8 \mathrm{mg}$ in four patients, losartan $25 \mathrm{mg}$ in four patients, olmesartan $10 \mathrm{mg}$ in three patients and valsartan $40 \mathrm{mg}$ in two patients. Except one patient in the ACEI/ARB group, all the patients with HT continued to receive their antihypertensive drugs at least during their chemotherapy. One patient in the ACEI/ARB group stopped taking valsartan 1 month after starting chemotherapy because of the decrease in blood pressure. Patient characteristics of the ACEI/ARB group $(n=27)$, the non-ACEI/ARB with HT group $(n=25)$, and the non-HT group $(n=103)$ are shown in Table 2.
Table I Number of patients receiving antihypertensive drugs

\begin{tabular}{lc}
\hline Drugs & Number of patients \\
\hline ACEI & 6 \\
Enalapril & 4 \\
Lisinopril & 1 \\
Temocapril & 1 \\
ARB & 21 \\
Candesartan & 12 \\
Losartan & 4 \\
Olmesartan & 3 \\
Valsartan & 2 \\
Calcium-channel blockers & 22 \\
Amlodipine & 8 \\
Nifedipine & 6 \\
Manidipine & 4 \\
Diltiazem & 4 \\
B-Blockers & 3 \\
Atenolol & 2 \\
Betaxolol & 1 \\
\hline Abbrevidion: ACE & 2 \\
\hline
\end{tabular}

Abbreviations: $\mathrm{ACE}=$ angiotensin I-converting enzyme inhibitor; $\mathrm{ARB}=$ angiotensin II type-I receptor blocker.

Table 2 Patient characteristics

\begin{tabular}{|c|c|c|c|c|}
\hline Characteristics & $\begin{array}{c}\text { ACEI/ARB } \\
(n=27)\end{array}$ & $\begin{array}{c}\text { Non-ACEI/ARB } \\
\text { with HT }(n=25)\end{array}$ & $\begin{array}{l}\text { Non-HT } \\
(n=103)\end{array}$ & $P$-value \\
\hline $\begin{array}{l}\text { Median age, } \\
\text { years (range) }\end{array}$ & 7II (53-87) & $73(56-88)$ & $63(4 \mid-89)$ & $<0.001$ \\
\hline $\begin{array}{l}\text { Gender } \\
\text { (male/female) }\end{array}$ & $15 / 12$ & $11 / 14$ & $58 / 45$ & 0.538 \\
\hline PS & & & & 0.621 \\
\hline 0 & 14 & 11 & 40 & \\
\hline 1 & 9 & 13 & 47 & \\
\hline 2 & 4 & 1 & 14 & \\
\hline 3 & 0 & 0 & 2 & \\
\hline Location & & & & 0.355 \\
\hline Head & 12 & 16 & 53 & \\
\hline Body/tail & 15 & 9 & 50 & \\
\hline Stage & & & & 0.668 \\
\hline $\begin{array}{l}\text { Locally } \\
\text { advanced }\end{array}$ & 12 & 10 & 40 & \\
\hline Metastatic & 15 & 15 & 63 & \\
\hline \multicolumn{5}{|c|}{ Site of metastasis, $n(\%)$} \\
\hline Liver & $10(37.0 \%)$ & $12(48.0 \%)$ & $46(44.7 \%)$ & 0.942 \\
\hline Lung & I (3.7\%) & $3(12.0 \%)$ & $13(12.6 \%)$ & 0.473 \\
\hline Lymph node & $13(48.2 \%)$ & $12(48.0 \%)$ & $50(48.5 \%)$ & 1.000 \\
\hline Peritoneum & $3(11.1 \%)$ & I (4.0\%) & $15(14.6 \%)$ & 0.412 \\
\hline $\begin{array}{l}\text { Median CEA, } \\
\mathrm{ng} \mathrm{m}^{-1} \text { (range) }\end{array}$ & $4.0(0.8-120.2)$ & ) $6.1(2.4-2964.3)$ & $5.7(I-2756.9)$ & 0.201 \\
\hline $\begin{array}{l}\text { Median CA I9-9, } \\
\cup \mathrm{ml}^{-1} \text { (range) }\end{array}$ & $490(I-145600)$ & $421(1-102100)$ & $324(1-182600)$ & 0.788 \\
\hline Hypertension & 27 & 25 & 0 & $<0.001$ \\
\hline
\end{tabular}

Abbreviations: $\quad A C E I=$ angiotensin $\quad$-converting enzyme inhibitor; $A R B=$ angiotensin II type-I receptor blocker; CAI9-9=carbohydrate antigen 19-9; $\mathrm{CEA}=$ carcinoembryonic antigen; $\mathrm{HT}=$ hypertension; $\mathrm{PS}=$ performance status.

Baseline characteristics did not differ significantly among groups, apart from age and HT medications. The mean RDI of gemcitabine was $67.3 \%$ in the ACEI/ARB group, $64.6 \%$ in the non-ACEI/ARB with HT group, and $66.4 \%$ in the non-HT group $(P=0.914)$. At the time of analysis, five patients in the ACEI/ARB group and two patients each in the non-ACEI/ARB with HT and non-HT groups continued to receive gemcitabine without disease progression, with a median follow-up time of 7.9 months (range, 5.2-17.3 months). Among 146 patients who showed disease progression during 


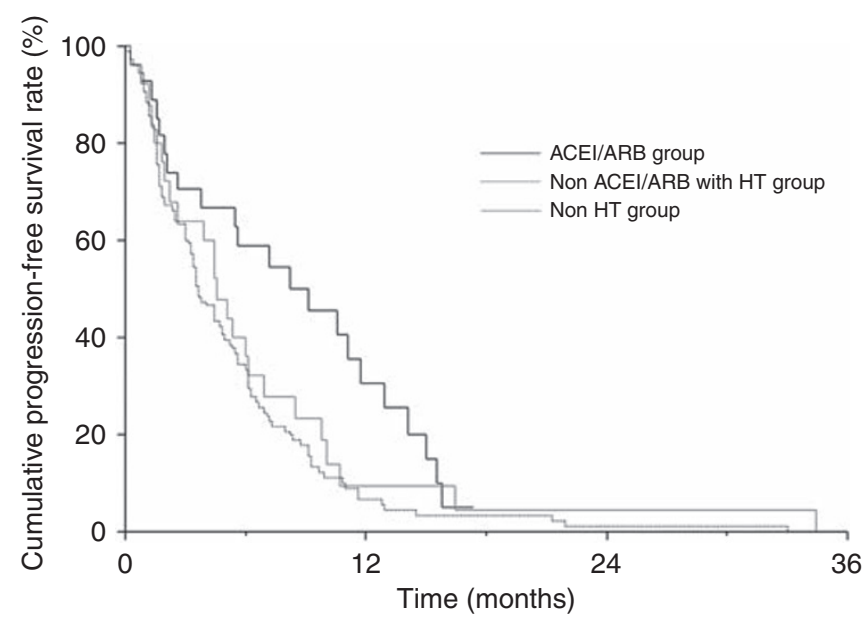

Figure I Kaplan-Meier curves for progression-free survival by treatment groups. The median progression-free survival was 8.7 months in the ACEI/ARB group, 4.5 months in the non-ACEI/ARB with HT group, and 3.6 months in the non-HT group.

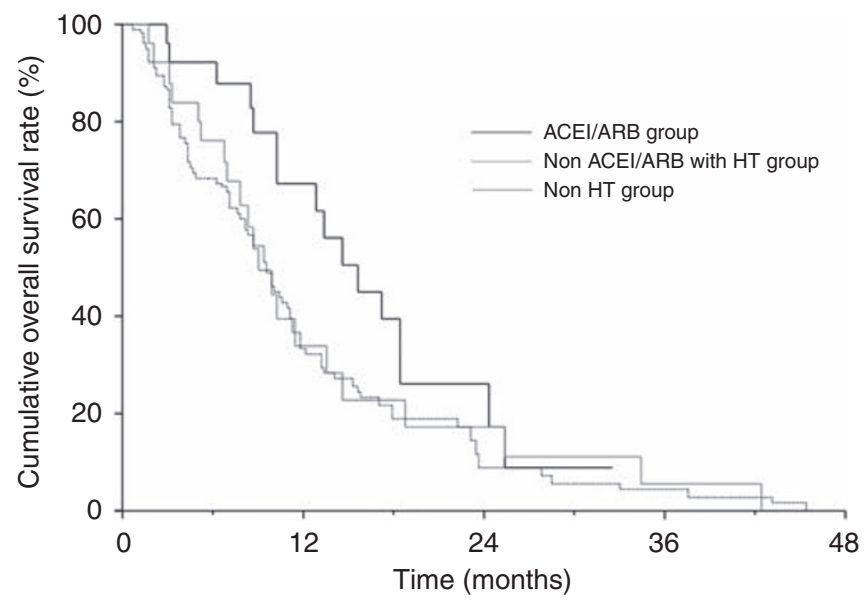

Figure 2 Kaplan-Meier curves for overall survival by treatment groups. The median overall survival was 15.1 months in the ACEI/ARB group, 8.9 months in the non-ACEI/ARB with HT group, and 9.5 months in the nonHT group.

gemcitabine treatment, second-line chemotherapy was administered in $23.8 \%$ of the ACEI/ARB group, $52.2 \%$ of the non-ACEI/ ARB with HT group, and $33.7 \%$ of the non-HT group $(P=0.134)$. Four patents $(2.6 \%)$ were lost to follow after disease progression; one patient in the ACEI/ARB group, one patient in the non-ACEI/ ARB with HT group, and two patients in the non-HT Group. The median follow-up period of these four patients was of 7.7 months.

\section{Impact of ACEIs/ARBs on clinical outcomes}

Response rates were comparable among the three groups; $3.7 \%$ in the ACEI/ARB group, $4.0 \%$ in the non-ACEI/ARB with HT group, and $2.9 \%$ in the non-HT group $(P=0.485)$, whereas the disease control rate was $63.0 \%$ in the ACEI/ARB group compared with $36.0 \%$ in the non-ACEI/ARB with HT group and $44.7 \%$ in the nonHT group $(P=0.131)$. The median PFS (Figure 1$)$ was 8.7 months (95\% confidence interval (CI), 2.6-11.1) in the ACEI/ARB group, 4.5 months $(95 \% \mathrm{CI}, 2.2-6.1)$ in the non-ACEI/ARB with HT group, and 3.6 months (95\% CI, 3.1-4.8) in the non-HT group ( $P=0.015$ by log-rank test). The median OS (Figure 2) was 15.1
Table 3 Univariate and multivariate analyses for progression-free survival

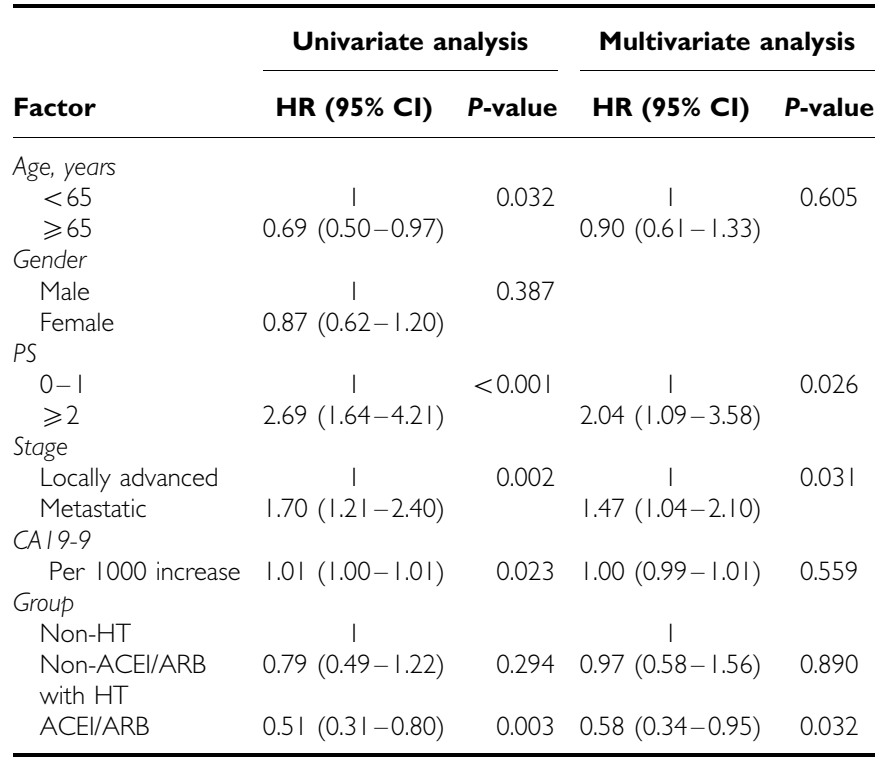

Abbreviations: $\mathrm{ACE}=$ angiotensin $\mathrm{I}$-converting enzyme inhibitor; $\mathrm{ARB}=$ angiotensin |l type-I receptor blocker; CAI9-9= carbohydrate antigen 19-9; Cl=confidence interval; $\mathrm{HR}=$ hazard ratio; $\mathrm{HT}=$ hypertension; $\mathrm{PS}=$ performance status.

months (95\% CI, 10.2-18.5) in the ACEI/ARB group, 8.9 months (95\% CI, 6.7-11.4) in the non-ACEI/ARB with HT group, and 9.5 months $(95 \% \mathrm{CI}, 7.8-11.2)$ in the non-HT group $(P=0.140$ by logrank test). There were no significant differences between patients taking ACEIs and ARBs. The median PFS was 10.6 months $(95 \%$ CI, $1.5-15.1)$ in patients taking ACEIs and 8.2 months $(95 \% \mathrm{CI}$, $2.0-12.9)$ in patients taking ARBs $(P=0.756$ by log-rank test). The median OS was 13.3 months $(95 \% \mathrm{CI}, 3.0-24.6)$ in patients taking ACEIs and 15.6 months (95\% CI, 8.7-25.4) in patients taking ARBs ( $P=0.794$ by log-rank test).

Although patient characteristics of the three groups were similar among groups except for age and HT medications, we performed Cox proportional hazard analyses to exclude the possible influence of confounding prognostic factors. The Cox univariate and multivariate analyses for PFS and OS are shown in Tables 3 and 4, respectively. The use of ACEIs/ARBs remained significant as a prognostic factor for both PFS and OS, in addition to the previously reported prognostic factors, PS and disease stage. The hazard ratios for the ACEI/ARB group against the non-HT group were $0.58(P=0.032)$ for PFS and $0.52(P=0.014)$ for OS. Those for the non-ACEI/ARB group were $0.97(P=0.890)$ for PFS and 1.23 $(P=0.430)$ for OS.

\section{DISCUSSION}

This retrospective study is the first report to clarify the clinical impact of the use of ACEIs or ARBs in pancreatic cancer. The use of ACEIs or ARBs was associated with longer PFS and OS in patients with advanced pancreatic cancer receiving gemcitabine monotherapy. These data suggest that inhibition of the RAS in human pancreatic cancer may inhibit tumour growth and improve survival, in accordance with previous in vitro studies and in vivo animal studies.

ACEIs and ARBs are widely used as antihypertensive drugs, and the reports of organ protective effects (Grandi and Maresca, 2006) by ACEIs are increasing, including inhibition of cardiac hypertrophy, diabetic nephropathy, and diabetic retinopathy. With respect to anticancer effects, Lever et al (1998) reported that the long-term use of ACEIs reduced the incidence of cancer in a 
Table 4 Univariate and multivariate analyses for overall survival

\begin{tabular}{|c|c|c|c|c|}
\hline \multirow[b]{2}{*}{ Factor } & \multicolumn{2}{|c|}{ Univariate analysis } & \multicolumn{2}{|c|}{ Multivariate analysis } \\
\hline & HR $(95 \% \mathrm{Cl})$ & $P$-value & HR (95\% Cl) & $P$-value \\
\hline \multicolumn{5}{|l|}{ Age, years } \\
\hline $\begin{array}{l}<65 \\
\geqslant 65\end{array}$ & $\begin{array}{c}1 \\
0.76(0.53-1.10)\end{array}$ & 0.142 & & \\
\hline \multicolumn{5}{|l|}{ Gender } \\
\hline $\begin{array}{l}\text { Male } \\
\text { Female }\end{array}$ & $\begin{array}{c}1 \\
0.69(0.48-0.98)\end{array}$ & 0.041 & $\frac{1}{1} 0.59(0.40-0.86)$ & 0.006 \\
\hline \multicolumn{5}{|l|}{ PS } \\
\hline $\begin{array}{l}0-1 \\
\geqslant 2\end{array}$ & $\begin{array}{c}1 \\
4.14 \\
(2.42-6.76)\end{array}$ & $<0.001$ & $\begin{array}{c}1 \\
4.08(2.22-7.05)\end{array}$ & $<0.001$ \\
\hline \multicolumn{5}{|l|}{ Stage } \\
\hline $\begin{array}{l}\text { Locally advanced } \\
\text { Metastatic }\end{array}$ & $\begin{array}{c}1 \\
1.65(|.| 4-2.4 \mid)\end{array}$ & 0.007 & $\begin{array}{c}1 \\
1.69(1.16-2.47)\end{array}$ & 0.030 \\
\hline \multicolumn{5}{|l|}{ CA19-9 } \\
\hline Per 1000 increase & $1.01(1.01-1.02)$ & 0.001 & $1.01(1.00-1.01)$ & 0.058 \\
\hline \multicolumn{5}{|l|}{ Group } \\
\hline $\begin{array}{l}\text { Non-ACEI/ARB } \\
\text { with HT }\end{array}$ & $0.92(0.55-1.45)$ & 0.718 & $1.23(0.73-1.98)$ & 0.430 \\
\hline ACEI/ARB & $0.59(0.33-0.97)$ & 0.038 & $0.52(0.29-0.88)$ & 0.014 \\
\hline
\end{tabular}

Abbreviations: $\mathrm{ACEI}=$ angiotensin l-converting enzyme inhibitor; $\mathrm{ARB}=$ angiotensin || type-I receptor blocker; CAI9-9= carbohydrate antigen 19-9; Cl= confidence interval; $\mathrm{HR}=$ hazard ratio; $\mathrm{HT}=$ hypertension; $\mathrm{PS}=$ performance status.

prospective cohort study, though they did not explore the underlying mechanisms. Since then, in addition to cardiovascular homostasis by the systemic RAS, increasing evidence indicates a role of the local RAS in various aspects of carcinogenesis, including angiogenesis, cell proliferation, apoptosis, and inflammation (Ager et al, 2008; Khakoo et al, 2008). On the other hand, a meta-analysis denied the reduced cancer incidence with ACEIs (Coleman et al, 2008) and the increased risk of cancer incidence was also reported with ARBs (Sipahi et al, 2010). Both the clinical impact of inhibition of RAS on cancer incidence and its underlying mechanism remains unclear.

The existence of the local RAS was first reported in the canine pancreas in 1991 (Chappell et al, 1991) and in the human pancreas in 1999 (Tahmasebi et al, 1999). The local pancreatic RAS has been implicated in various physiological conditions including pancreatitis, fibrosis, and diabetes mellitus (Leung, 2007). The involvement of the local RAS in pancreatic cancer was suggested because of the expression of angiotensin II (Ohta et al, 2003) and the angiotensin II type-1 receptor (Fujimoto et al, 2001) in human pancreatic cancer. The ACEIs and ARBs inhibit pancreatic cancer cell proliferation in vitro (Arafat et al, 2007) and also slow murine pancreatic cancer progression in vivo via down-regulation of VEGF expression (Noguchi et al, 2009; Fendrich et al, 2010). Inhibition of RAS is also reported to induce apoptosis in pancreatic cancer cells (Amaya et al, 2004; Gong et al, 2010). Accordingly, these drugs were suggested to be potential treatments for pancreatic cancer or for the prevention of pancreatic cancer. However, the clinical impact of ACEIs and ARBs in pancreatic cancer treatment has not been fully clarified. With respect to other cancer types, a pilot study reported that ARBs had cytostatic activity in hormone-refractory prostate cancer, as indicated by decreased prostate-specific antigen levels (Uemura et al, 2005), and the addition of ACEIs/ARBs to platinum-based chemotherapy was associated with prolonged survival in patients with advanced non-small cell lung cancer in a retrospective study (Wilop et al, 2009). ACEIs in combination with vitamin $\mathrm{K}$ were also reported to suppress the recurrence of hepatocellular carcinoma in a prospective study (Yoshiji et al, 2009).

It is possible that ACEIs and ARBs have different influences on cancer because ACEIs block both angiotensin II type-1 and type-2 receptors, whereas ARBs block only type-1 receptor. The role of angiotensin II type-2 receptor is less investigated than angiotensin II type-1 receptor, which is shown to induce angiogenesis, proliferation, and inflammation. Angiotensin II type-2 receptor is reported to be both anti- and pro-angiogenetic (Ager et al, 2008). In this study, there were no significant differences in survival between patients taking ACEIs and ARBs. Our study population was too small to analyze the differences between these two types of drugs.

The disappointing results of combination therapy with gemcitabine and cytotoxic drugs have led to intense investigation of molecular target drugs for pancreatic cancer (Burris and Rocha-Lima, 2008). Inhibition of VEGF or EGFR failed to demonstrate significant survival prolongation except one trial with erlotinib (Moore et al, 2007). The inhibition of RAS by ACEI or ARB reportedly influences multiple pathways including angiogenesis, proliferation, and apoptosis, and can be a safe and inexpensive strategy against pancreatic cancer, but a prospective study is warranted to evaluate antitumour effects by the inhibition of RAS.

This study had some limitations. As this was a retrospective study in a single institution and the sample size of the ACEI/ARB group was small, unknown sources of bias may exist in the findings. However, other than age and HT medications, no significant differences were detected in patient characteristics among groups, and the multivariate analysis revealed that ACEI/ ARB use remained a significant prognostic factor for both PFS and OS, though we cannot fully correct the bias that patients with HT were much older than patients without HT. Gemcitabine dose intensity and the induction rate of second-line chemotherapy were also similar in the three groups. The results of the non-ACEI/ARB with HT group also excluded the possibility that patients who did not receive antihypertensive drugs had a poorer prognosis. However, a prospective study with a larger population is warranted to confirm our hypothesis.

In conclusion, our retrospective analysis suggests that ACEIs or ARBs in combination with gemcitabine may improve clinical outcomes in patients with advanced pancreatic cancer. We have started a phase I trial of candesartan in combination with gemcitabine, which is currently ongoing (UMIN registration number 000002152).

\section{Conflict of interest}

The authors declare no conflict of interest.

\section{REFERENCES}

Ager EI, Neo J, Christophi C (2008) The renin-angiotensin system and malignancy. Carcinogenesis 29(9): 1675-1684

Amaya K, Ohta T, Kitagawa H, Kayahara M, Takamura H, Fujimura T, Nishimura G, Shimizu K, Miwa K (2004) Angiotensin II activates MAP kinase and NF-kappaB through angiotensin II type I receptor in human pancreatic cancer cells. Int J Oncol 25(4): 849-856

Arafat HA, Gong Q, Chipitsyna G, , Rizvi A, , Saa CT, Yeo CJ (2007) Antihypertensives as novel antineoplastics: angiotensin-I-converting 
enzyme inhibitors and angiotensin II type 1 receptor blockers in pancreatic ductal adenocarcinoma. J Am Coll Surg 204(5): 996-1005; discussion 1005-1006

Berlin JD, Catalano P, Thomas JP, Kugler JW, Haller DG, Benson III AB (2002) Phase III study of gemcitabine in combination with fluorouracil versus gemcitabine alone in patients with advanced pancreatic carcinoma: Eastern Cooperative Oncology Group Trial E2297. J Clin Oncol 20(15): $3270-3275$

Burris III H, Rocha-Lima C (2008) New therapeutic directions for advanced pancreatic cancer: targeting the epidermal growth factor and vascular endothelial growth factor pathways. Oncologist 13(3): 289-298

Burris III HA, Moore MJ, Andersen J, Green MR, Rothenberg ML, Modiano MR, Cripps MC, Portenoy RK, Storniolo AM, Tarassoff P, Nelson R, Dorr FA, Stephens CD, Von Hoff DD (1997) Improvements in survival and clinical benefit with gemcitabine as first-line therapy for patients with advanced pancreas cancer: a randomized trial. J Clin Oncol 15(6): $2403-2413$

Chappell MC, Millsted A, Diz DI, Brosnihan KB, Ferrario CM (1991) Evidence for an intrinsic angiotensin system in the canine pancreas. J Hypertens 9(8): $751-759$

Coleman CI, Baker WL, Kluger J, White CM (2008) Antihypertensive medication and their impact on cancer incidence: a mixed treatment comparison meta-analysis of randomized controlled trials. J Hypertens 26(4): $622-629$

Conroy T, Desseigne F, Ychou M, Ducreux M, Bouche O, Guimbaud R, Becouarn Y, Montoto-Grillot C, Gourgou-Bourgade S, Adenis A, , Group F-FP (2010) Randomized phase III trial comparing FOLFIRINOX (F: $5 \mathrm{FU} /$ leucovorin $[\mathrm{LV}]$, irinotecan $[\mathrm{I}]$, and oxaliplatin [O]) versus gemcitabine $(G)$ as first-line treatment for metastatic pancreatic adenocarcinoma (MPA): preplanned interim analysis results of the PRODIGE 4/ACCORD 11 trial. J Clin Oncol 28(15s): 4010

Cunningham D, Chau I, Stocken DD, Valle JW, Smith D, Steward W, Harper PG, Dunn J, Tudur-Smith C, West J, Falk S, Crellin A, Adab F, Thompson J, Leonard P, Ostrowski J, Eatock M, Scheithauer W, Herrmann R, Neoptolemos JP (2009) Phase III randomized comparison of gemcitabine versus gemcitabine plus capecitabine in patients with advanced pancreatic cancer. J Clin Oncol 27(33): 5513-5518

Fendrich V, Chen NM, Neef M, Waldmann J, Bucholz M, Feldmann G, Slater EP, Maitra A, Bartsch DK (2010) The angiotensin-I-converting enzyme inhibitor enalapril and aspirin delay progression of pancreatic intraepithelial neoplasia and cancer formation in a genetically engineered mouse model of pancreatic cancer. Gut 59(5): 630-637

Fujimoto Y, Sasaki T, Tsuchida A, Chayama K (2001) Angiotensin II type 1 receptor expression in human pancreatic cancer and growth inhibition by angiotensin II type 1 receptor antagonist. FEBS Lett 495(3): $197-200$

Gong Q, Davis M, Chipitsyna G, Yeo CJ, Arafat HA (2010) Blocking angiotensin II type 1 receptor triggers apoptotic cell death in human pancreatic cancer cells. Pancreas 39(5): 595-603

Grandi AM, Maresca AM (2006) Blockade of the renin-angiotensinaldosterone system: effects on hypertensive target organ damage. Cardiovasc Hematol Agents Med Chem 4(3): 219-228

Herrmann R, Bodoky G, Ruhstaller T, Glimelius B, Bajetta E, Schuller J, Saletti P, Bauer J, Figer A, Pestalozzi B, Kohne CH, Mingrone W, Stemmer SM, Tamas K, Kornek GV, Koeberle D, Cina S, Bernhard J, Dietrich D, Scheithauer W (2007) Gemcitabine plus capecitabine compared with gemcitabine alone in advanced pancreatic cancer: a randomized, multicenter, phase III trial of the Swiss Group for Clinical Cancer Research and the Central European Cooperative Oncology Group. J Clin Oncol 25(16): 2212-2217

Khakoo AY, Sidman RL, Pasqualini R, Arap W (2008) Does the reninangiotensin system participate in regulation of human vasculogenesis and angiogenesis? Cancer Res 68(22): 9112-9115

Kindler HL, Niedzwiecki D, Hollis D, Sutherland S, Schrag D, Hurwitz H, Innocenti F, Mulcahy MF, O'Reilly E, Wozniak TF, Picus J, Bhargava P, Mayer RJ, Schilsky RL, Goldberg RM (2010) Gemcitabine plus bevacizumab compared with gemcitabine plus placebo in patients with advanced pancreatic cancer: phase III trial of the Cancer and Leukemia Group B (CALGB 80303). J Clin Oncol 28(22): 3617-3622

Leung PS (2007) The physiology of a local renin-angiotensin system in the pancreas. J Physiol 580(Part 1): 31-37

Lever AF, Hole DJ, Gillis CR, McCallum IR, McInnes GT, MacKinnon PL, Meredith PA, Murray LS, Reid JL, Robertson JW (1998) Do inhibitors of angiotensin-I-converting enzyme protect against risk of cancer? Lancet 352(9123): $179-184$
Louvet C, Labianca R, Hammel P, Lledo G, Zampino MG, Andre T, Zaniboni A, Ducreux M, Aitini E, Taieb J, Faroux R, Lepere C, de Gramont A (2005) Gemcitabine in combination with oxaliplatin compared with gemcitabine alone in locally advanced or metastatic pancreatic cancer: results of a GERCOR and GISCAD phase III trial. J Clin Oncol 23(15): 3509-3516

Moore MJ, Goldstein D, Hamm J, Figer A, Hecht JR, Gallinger S, Au HJ, Murawa P, Walde D, Wolff RA, Campos D, Lim R, Ding K, Clark G, Voskoglou-Nomikos T, Ptasynski M, Parulekar W (2007) Erlotinib plus gemcitabine compared with gemcitabine alone in patients with advanced pancreatic cancer: a phase III trial of the National Cancer Institute of Canada Clinical Trials Group. J Clin Oncol 25(15): 1960-1966

Nakai Y, Isayama H, Sasaki T, Sasahira N, Hirano K, Tsujino T, Tada M, Omata M, Koike K, Group GS (2010) A multicenter randomized controlled trial of gemcitabine $(G)$ alone versus gemcitabine and S-1 combination therapy (GS) in patients with unresectable advanced pancreatic cancer (PC): GEMSAP study. J Clin Oncol 28(15s): 4037

Nakai Y, Isayama H, Sasaki T, Sasahira N, Ito Y, Kogure H, Togawa O, Matsubara S, Arizumi T, Yagioka H, Yashima Y, Kawakubo K, Mizuno S, Yamamoto K, Hirano K, Tsujino T, Ijichi H, Toda N, Tada M, Kawabe T, Omata M (2009) A pilot study for combination chemotherapy using gemcitabine and S-1 for advanced pancreatic cancer. Oncology 77(5): $300-303$

Noguchi R, Yoshiji H, Ikenaka Y, Namisaki T, Kitade M, Kaji K, Yoshii J, Yanase K, Yamazaki M, Tsujimoto T, Kawaratani H, Fukui H (2009) Synergistic inhibitory effect of gemcitabine and angiotensin type-1 receptor blocker, losartan, on murine pancreatic tumor growth via antiangiogenic activities. Oncol Rep 22(2): 355-360

Ohta T, Amaya K, Yi S, Kitagawa H, Kayahara M, Ninomiya I, Fushida S, Fujimura T, Nishimura G, Shimizu K, Miwa K (2003) Angiotensin converting enzyme-independent, local angiotensin II-generation in human pancreatic ductal cancer tissues. Int J Oncol 23(3): 593-598

Philip PA, Benedetti J, Corless CL, Wong R, O’Reilly EM, Flynn PJ, Rowland KM, Atkins JN, Mirtsching BC, Rivkin SE, Khorana AA, Goldman B, Fenoglio-Preiser CM, Abbruzzese JL, Blanke CD (2010) Phase III study comparing gemcitabine plus cetuximab versus gemcitabine in patients with advanced pancreatic adenocarcinoma: Southwest Oncology Groupdirected intergroup trial S0205. J Clin Oncol 28(22): 3605-3610

Reni M, Cordio S, Milandri C, Passoni P, Bonetto E, Oliani C, Luppi G, Nicoletti R, Galli L, Bordonaro R, Passardi A, Zerbi A, Balzano G, Aldrighetti L, Staudacher C, Villa E, Di Carlo V (2005) Gemcitabine versus cisplatin, epirubicin, fluorouracil, and gemcitabine in advanced pancreatic cancer: a randomised controlled multicentre phase III trial. Lancet Oncol 6(6): 369-376

Sipahi I, Debanne SM, Rowland DY, Simon DI, Fang JC (2010) Angiotensinreceptor blockade and risk of cancer: meta-analysis of randomised controlled trials. Lancet Oncol 11(7): 627-636

Tahmasebi M, Puddefoot JR, Inwang ER, Vinson GP (1999) The tissue renin-angiotensin system in human pancreas. J Endocrinol 161(2): $317-322$

Therasse P, Arbuck SG, Eisenhauer EA, Wanders J, Kaplan RS, Rubinstein L, Verweij J, Van Glabbeke M, van Oosterom AT, Christian MC, Gwyther SG (2000) New guidelines to evaluate the response to treatment in solid tumors. European Organization for Research and Treatment of Cancer National Cancer Institute of the United States, National Cancer Institute of Canada. J Natl Cancer Inst 92(3): 205-216

Uemura H, Hasumi H, Kawahara T, Sugiura S, Miyoshi Y, Nakaigawa N, Teranishi J, Noguchi K, Ishiguro H, Kubota Y (2005) Pilot study of angiotensin II receptor blocker in advanced hormone-refractory prostate cancer. Int J Clin Oncol 10(6): 405-410

Van Cutsem E, Vervenne WL, Bennouna J, Humblet Y, Gill S, Van Laethem JL, Verslype C, Scheithauer W, Shang A, Cosaert J, Moore MJ (2009) Phase III trial of bevacizumab in combination with gemcitabine and erlotinib in patients with metastatic pancreatic cancer. J Clin Oncol 27(13): $2231-2237$

Wilop S, von Hobe S, Crysandt M, Esser A, Osieka R, Jost E (2009) Impact of angiotensin I converting enzyme inhibitors and angiotensin II type 1 receptor blockers on survival in patients with advanced non-small-cell lung cancer undergoing first-line platinum-based chemotherapy. J Cancer Res Clin Oncol 135(10): 1429-1435

Yoshiji H, Noguchi R, Toyohara M, Ikenaka Y, Kitade M, Kaji K, Yamazaki M, Yamao J, Mitoro A, Sawai M, Yoshida M, Fujimoto M, Tsujimoto T, Kawaratani H, Uemura M, Fukui H (2009) Combination of vitamin K2 and angiotensin-converting enzyme inhibitor ameliorates cumulative recurrence of hepatocellular carcinoma. J Hepatol 51(2): 315-321 